\title{
Perbandingan Sifat Fungsional Pati Sitrat Skala Laboratorium dan Komersial Sebagai Bahan Pelapis Buah Terolah Minimal
}

\section{Comparison of citrate starch functional properties in laboratory and commercial scale as a minimally processed fruit coating material}

\author{
Dyah Ayu Larasati ${ }^{1 *}$, Indah Yuliasih² \\ ${ }^{1}$ Program Studi Teknologi Industri Pertanian, Jurusan Teknik Proses dan Hayati, Institut Teknologi Sumatera, Way Hui, \\ Lampung Selatan, 35365, Indonesia \\ ${ }^{2}$ Departemen Teknologi Industri Pertanian, Fakultas Teknologi Pertanian, IPB University, Kampus IPB Dramaga, Bogor, \\ 16680, Indonesia \\ *E-mail: dyah.larasati@tip.itera.ac.id
}

Diterima: 27 Juni 2020; Disetujui: 7 Desember 2020

\begin{abstract}
ABSTRAK
Kecenderungan masyarakat modern untuk mengkonsumsi makanan yang sehat namun keterbatasan waktu menyediakan, menyebabkan produk buah terolah minimal diminati karena praktis dan porsi penyajiannya sesuai dengan kebutuhan. Kelemahan buah terolah minimal adalah cepat rusak dan umur simpannya pendek sehingga mutunya menurun dengan cepat. Apel merupakan salah satu buah yang banyak diminati masyarakat dan tersedia sepanjang musim, namun jika diproses menjadi buah terolah minimal, akan terjadi reaksi pencoklatan enzimatis (enzymatic browning). Pelapisan berbahan dasar pati sitrat merupakan alternatif untuk mengurangi terjadinya reaksi enzimatis tersebut. Terdapat dua skala produksi pati sitrat pada penelitian ini yaitu skala laboratorium dan komersial. Perbedaan kedua skala produksi tersebut terdapat pada agen ikat silang dan peralatan yang digunakan. Pada skala laboratorium menggunakan asam sitrat teknis dan oven, sedangkan skala komersial menggunakan asam sitrat yang banyak tersedia di pasar yaitu 'Citrun' dan tray dryer. Tujuan penelitian ini yaitu mendapatkan pati sitrat skala laboratorium dan komersial serta membandingkan sifat fungsionalnya. Terdapat perbedaan sifat fungsional pati sitrat skala laboratorium dengan skala komersial. Persentase kelarutan, swelling power, dan freeze thaw stability pada pati sitrat skala komersial lebih tinggi dibandingkan skala laboratorium, yaitu sebesar $12.40,4.79$, dan $3.21 \%$. Namun nilai swelling power dan freeze thaw stability tidak berpengaruh nyata ( $p>0.05$ ) sedangkan persentase kejernihan pasta $1 \%$ mengalami penurunan sebesar $8.04 \%$
\end{abstract}

Kata kunci: buah terolah minimal; pati sitrat; sifat fungsional; skala komersial

\section{ABSTRACT}

Trend of modern society to consume healthy food but have limited time to providing, causing minimally processed fruit product in demand because of it was practical and have portion as a needed. The weakness of minimally processed fruit was quickly damaged and short shelf life so that the quality decreased rapidly. Apples were one of the most popular fruits and available in all seasons, but if processed into minimally processed fruit, enzymatic browning reaction would occur. Citrate starch-based coating was an alternative to reduce the occurrence of enzymatic reaction. There were two scale production of citrate starch in this research that was laboratory and commercial scale. The difference between the two production scales was found in the crosslinking agent and the equipment used. On a laboratory scale using citric acid technical and oven for drying, while commercial scale using "Citrun" citric acid which was available in the market and tray dryer. The objective of this research was to get laboratory and commercial scale of citrate starch and compare its functional properties. There were differences of functional properties citrate starch of laboratory scale with commercial scale. Percentage of solubility, swelling power, and freeze thaw stability on commercial scale citrate starch were higher than laboratory scale, which was $12.40,4.79$, and $3.21 \%$. However, the value of swelling power and freeze thaw stability was not significant ( $\alpha>0.05$ ), while the percentage of paste clarity $1 \%$ decreased by $8.04 \%$.

Keywords: minimally processed fruit; citrate starch; fuctional properties; commercial scale

\section{PENDAHULUAN}

Kebutuhan mengkonsumsi produk sehat dan kurangnya waktu untuk memasak menyebabkan popularitas dari produk yang diolah minimal (minimally processed product) juga meningkat. Pengolahan minimal (minimal processing) pada buah dan sayur atau dikenal pula dengan istilah potong segar (fresh-cut) merupakan pengolahan yang melibatkan pencucian, pengupasan, dan pengirisan sebelum dikemas dan menggunakan suhu rendah untuk penyimpanan sehingga mudah dikonsumsi tanpa menghilangkan kesegaran dan nilai gizi yang dikandungnya (Laurila \& Ahvenainen, 2002).

Apel (Phyrus Marus L.) merupakan salah satu buah subtropis Indonesia yang tersedia sepanjang musim dan diminati oleh masyarakat. Badan Pusat Statistika telah mencatat data impor pada buah apel terus mengalami peningkatan. Pada Neraca Bahan Makanan Indonesia 2017-2019, impor buah apel mencapai 137,23 juta ton/ tahun (Badan Ketahanan Pangan \& Statistik, 2019). Inovasi pengolahan minimal terhadap buah apel selain bertujuan untuk diversifikasi produk, juga dapat mempersingkat waktu 
untuk mengkonsumsi sehingga lebih praktis. Namun, buah apel mengalami keterbatasan yaitu cepat berubah warna menjadi cokelat setelah proses pemotongan. Pencoklatan (browning) pada buah apel disebabkan oleh aktifnya enzim polifenol oksidase membentuk senyawa melanin menimbulkan warna coklat pada buah atau sayuran (Camirand et al., 1994). Padahal warna menjadi atribut mutu yang sangat penting pada produk buah-buahan atau sayuran terolah minimal (Lin D \& Zhao Y, 2007).

Salah satu cara untuk mengurangi pencoklatan pada buah apel yaitu dilakukan pelapisan (coating) terhadap permukaannya. Permintaan pasar terhadap bahan dasar pembuat pelapis mulai diperhatikan seiring dengan berkembangnya penelitian yang dilakukan. Sebagian besar kebutuhan pati termodifikasi sebagai bahan baku pembuatan pelapis masih dipenuhi dengan produk impor. Diperkirakan, produk impor pati termodifikasi ke Indonesia tiap tahunnya mencapai US\$ 150 juta (Badan Pusat Statistika, 2011).

Indonesia memiliki banyak tanaman yang mengandung pati sebagai bahan dasar coating film. Menurut (Saputra et al., 2015), pati merupakan polisakarida yang penting dalam pembuatan coating film. Selain biayanya murah dan aman untuk dimakan (edible), pati memiliki sifat termoplastik yang baik. Pencampuran pati ke dalam pembuatan film menyebabkan interaksi sinergis yang baik dan dapat menghasilkan perbaikan karakteristik coating film. Kelemahan pati alami adalah memiliki sifat fungsional yang dapat menghambat pembentukan film. Sifat fungsional pati yang memengaruhi karakteristiknya sebagai bahan baku coating film buah terolah minimal meliputi kelarutan dan swelling power pada suhu $70^{\circ} \mathrm{C}$, kejernihan pasta $1 \%$, serta freeze thaw stability (Yuwono, S. et al., 2013). Modifikasi pati menjadi pati sitrat dapat meningkatkan sifat fungsionalnya (Larasati, 2017). Penelitian tersebut menggunakan agen ikat silang asam sitrat teknis dan alat pengering yaitu oven, dengan kapasitas $100 \mathrm{~g}$ dan rendemen yang dihasilkan $77,81 \%$. Jika produksi pati sitrat masih dalam skala laboratorium, maka potensi pemenuhan permintaan pasar akan rendah. Oleh karena itu, pada penelitian ini dilakukan proses pembuatan pati sitrat dengan skala komersial menggunakan agen ikat silang asam sitrat yang banyak tersedia di pasar yaitu "Citrun" dengan alat pengering tray dryer. Tujuan penelitian ini adalah mendapatkan pati sitrat skala laboratorium dan komersial serta membandingkan sifat fungsionalnya.

\section{METODE}

Bahan yang digunakan dalam penelitian ini adalah pati sagu (Metroxylon sp.) dari pabrik sagu di Tanah Sereal Bogor, asam sitrat merk "Citrun", asam sitrat teknis, akuades, $\mathrm{NaOH}$, dan bahan kimia analisa yang lain. Peralatan yang digunakan adalah alat pengering tipe rak (tray dryer) pintu ganda dengan sumber bahan bakar dari LPG dan listrik, oven pengering (Kirin oven electric KBO 190RAW), hot plate stirrer, dan peralatan analisa yang lain.

Tahap pertama adalah pembuatan pati sitrat. Metode pembuatan pati sitrat skala laboratorium yaitu sebanyak 40 $\mathrm{g}$ asam sitrat dilarutkan ke dalam $40 \mathrm{ml}$ aquades pada erlenmeyer $250 \mathrm{ml}$. Kemudian larutan diatur $\mathrm{pH}$-nya dengan $\mathrm{NaOH}$ pekat $(10 \mathrm{M})$ hingga $\mathrm{pH}$ menjadi 3,5 dan ditera hingga volume $100 \mathrm{ml}$. Sebanyak $100 \mathrm{~g}$ pati sagu dilarutkan dalam larutan asam sitrat hingga homogen, kemudian dituang ke dalam nampan pengering. Larutan dalam nampan disimpan pada suhu ruang selama 16 jam. Setelah itu, nampan dimasukkan ke dalam oven pada suhu $60^{\circ} \mathrm{C}$ selama 6 jam, dan pada suhu $130{ }^{\circ} \mathrm{C}$ selama 2 jam. Pati hasil pengeringan dicuci dengan aquades dan disaring menggunakan filter glass 3G-3 untuk membuang sisa asam sitrat yang tidak bereaksi dengan pati. Setelah itu pati dibilas dengan etanol $96 \%$ kemudian metanol. Pati yang dihasilkan dikeringanginkan dan dilakukan pengecilan ukuran hingga menghasilkan pati sitrat yang siap digunakan (Larasati, 2017).Proses pembuatan pati sitrat skala komersial menggunakan metode sebelumnya, namun mengalami sedikit modifikasi. Jumlah pati sagu yang digunakan sebanyak $1000 \mathrm{~g}$ dan alat pengering menggunakan pengering rak (tray dryer). Setelah tahapan pengeringan pada suhu $130{ }^{\circ} \mathrm{C}$ selama 2 jam, pati sitrat langsung dicuci dengan aquades, untuk memisahkan patinya, menggunakan metode pengendapan. Pencucian pati dengan aquades dilakukan hingga asam sitrat sisa yang tidak bereaksi hilang. Pati sitrat dikeringkan kembali pada tray dryer dengan suhu rendah $\left(50^{\circ} \mathrm{C}\right)$ hingga mencapai kadar air $8 \%$.

Tahapan selanjutnya adalah karakterisasi sifat fungsional pati sitrat. Sifat pati yang memengaruhi karakteristiknya sebagai bahan baku coating film adalah sifat fungsional. Analisis sifat fungsional pati sitrat, meliputi kelarutan dan swelling power (modifikasi metode (BelloPerez et al., 2010), kejernihan pasta pati 1\% (Perez et al., 2007), serta freeze thaw stability (\% sineresis) (Singh, 2004). Parameter kelarutan dan swelling power suatu pati dipengaruhi oleh sifat fisik dari pati yaitu ukuran granulanya. Semakin besar granulanya, maka semakin besar nilainya (Yuliasih et al., 2008). Rancangan percobaan yang digunakan adalah Rancangan Acak Lengkap Satu Faktor yaitu Skala Penelitian dengan 2 taraf yaitu 1=Skala Laboratorium, 2=Skala Komersial. Rancangan ini menggunakan ulangan sebanyak 2 kali. Model matematika yang digunakan adalah sebagai berikut:

$$
Y_{i j}=\mu+\tau_{i}+\varepsilon_{i j}
$$

$\begin{array}{ll}\text { Keterangan: } \\ \mathrm{Y}_{\mathrm{ij}} & : \text { hasil pengamatan } \\ \mu & : \text { nilai rata-rata umum } \\ \mathrm{T}_{\mathrm{i}} & : \text { pengaruh perlakuan } \mathrm{ke}-\mathrm{,}, \mathrm{i}=1,2 \\ \varepsilon_{\mathrm{ij}} & : \text { galat percobaan }\end{array}$

\section{HASIL DAN PEMBAHASAN}

Reaksi pati sagu dengan asam sitrat pada suhu tinggi akan menghasilkan produk pati sitrat. Asam sitrat akan kehilangan kandungan air saat dipanaskan dan berubah menjadi asam sitrat anhidrida yang dapat bereaksi dengan pati sagu membentuk pati sitrat. Karakterisasi sifat fungsional adalah suatu uji yang dilakukan untuk mengetahui karakteristik dari suatu bahan / produk. Hasil analisis sifat fungsional pati sitrat disajikan dalam Tabel 1

Kelarutan pati sitrat skala komersial pada suhu $70^{\circ} \mathrm{C}$ memiliki nilai yang lebih tinggi dibandingkan dengan kelarutan pati sitrat skala laboratorium yaitu sebesar $12,4 \%$, yang berarti mengalami peningkatan sebesar $5,51 \%$. Sifat kelarutan pati berhubungan dengan keberhasilan modifikasi dari suatu pati. Meningkatnya nilai kelarutan diduga akibat dari proses modifikasi yang kurang sempurna, sehingga tidak semua granula pati terikat silang dengan baik. Pati sitrat diproduksi dengan tujuan mendapatkan produk pati yang tidak larut air sehingga ketika diaplikasikan sebagai coating film dapat menghambat uap air yang masuk ke dalam produk yang dilapisi. Berdasarkan analisis ragam $(\alpha=0,05)$, skala produksi pati sitrat memiliki pengaruh nyata terhadap nilai kelarutan. Namun, jika dibandingkan dengan kelarutan pati alami sagu yaitu $20,44 \%$, kelarutan pati sitrat 
skala komersial memiliki nilai yang lebih rendah sehingga dapat diaplikasikan sebagai bahan dasar coating film.

Tabel 1. Hasil analisis sifat fungsional pati alami, pati sitrat skala laboratorium dan komersial

\begin{tabular}{lccc}
\hline \multicolumn{1}{c}{ Parameter } & $\begin{array}{c}\text { Pati } \\
\text { Alami }^{*}\end{array}$ & $\begin{array}{c}\text { Pati } \\
\text { Sitrat SL }\end{array}$ & $\begin{array}{c}\text { Pati } \\
\text { Sitrat SK }\end{array}$ \\
\hline $\begin{array}{l}\text { Kelarutan pada 70 } \\
{ }^{\circ} \mathrm{C}(\%)\end{array}$ & 20.44 & 6.89 & 12.4 \\
$\begin{array}{l}\text { Kejernihan pasta 1\% } \\
\text { (\%) }\end{array}$ & 27.60 & 96.31 & 88.27 \\
$\begin{array}{l}\text { Swelling power pada } \\
70{ }^{\circ} \mathrm{C}(\%)\end{array}$ & 68.92 & 4.25 & 4.79 \\
$\begin{array}{l}\text { Freeze thaw stability } \\
\text { (\% sineresis) }\end{array}$ & 12.96 & 2.78 & 3.21 \\
${ }^{*}$ (Larasati, 2017), SL : Skala laboratorium, SK: Skala komersial
\end{tabular}

Nilai kelarutan pati pada suhu $70{ }^{\circ} \mathrm{C}$ berhubungan dengan nilai kejernihan pastanya. Jika kelarutan naik, maka nilai kejernihan pasta akan menurun. Hal ini terlihat pada Tabel 1 yaitu nilai kejernihan pasta $1 \%$ pada pati sitrat skala komersial mengalami penurunan sebesar $8,04 \%$ dari pati sitrat skala laboratorium, yaitu sebesar $88,27 \%$. Namun, nilai kejernihan pasta tersebut masih tergolong tinggi. Hasil analisis ragam $(\alpha=0,05)$ menunjukkan bahwa skala produksi pati memiliki pengaruh nyata terhadap kejernihan pasta $1 \%$. Sifat kejernihan pasta $1 \%$ merupakan sifat fungsional pati yang wajib diketahui jika digunakan sebagai bahan dasar coating film. Semakin jernih pasta pati yang dihasilkan, maka mutu coating film yang dihasilkan akan semakin baik, karena tidak akan mengganggu permukaan bahan yang dilapisi.

Karakteristik lain yang penting untuk diketahui yaitu nilai swelling power pati sitrat. Pada aplikasi, nilai swelling power yang tinggi akan berpengaruh pada saat proses casting film, karena ketika proses penuangan ke plat kaca akan membentuk film yang tebal dan permukaannya tidak mulus. Salah satu tujuan dibuat pati sitrat adalah untuk menurunkan kekentalannya. Swelling power pada pati dipengaruhi oleh daya serap air (Jading et al., 2011). Semakin rendah daya serap air menyebabkan swelling power menurun yang berarti bahwa sifat pati semakin hidrofobik. Hasil penelitian pada Tabel 1 menunjukkan bahwa nilai swelling power pati sitrat skala komersial mengalami sedikit peningkatan yaitu sebesar $0,54 \%$. Peningkatan tersebut tidak berpengaruh signifikan yang didukung dengan hasil analisis ragam $(\alpha=0,05)$. Nilai swelling power yang rendah disebabkan adanya agen crosslinking yang berpenetrasi masuk ke dalam granula pati dan membentuk ikatan kovalen (Retnaningtyas \& Putri, 2014). Hal ini menyebabkan pati sitrat dapat dipanaskan sampai suhu tinggi tanpa merusak struktur granulanya. Sifat fisiologis ini akan memengaruhi stabilitas pati termodifikasi saat pemanasan pada proses pembuatan coating film.

Parameter yang digunakan untuk mengetahui stabilitas pati adalah persentase sineresis. Sineresis adalah keluarnya atau merembesnya cairan dari dalam gel (Winarno, 1992). Sifat freeze thaw stability ditunjukkan dengan nilai presentase sineresis patinya. Semakin tinggi persentase sineresis, semakin banyak air yang keluar, sehingga nilai freeze thaw stability-nya rendah. Freeze thaw stability yang dimiliki pati sitrat skala laboratorium dan komersial cukup rendah yaitu sebesar 2,78 dan $3,21 \%$. Nilai tersebut tidak memiliki pengaruh nyata berdasarkan hasil analisis ragam $(\alpha=0,05)$. Nilai yang rendah menunjukkan bahwa pati sitrat cukup stabil jika keluar masuk pada kondisi dingin dan ruang pada selang waktu tertentu.
Sifat kelarutan dan swelling power pati berhubungan dengan ukuran granulanya. Semakin besar ukuran granulanya maka semakin tinggi pula nilainya (Yuliasih et al., 2008). Ikatan hidrogen intermolekuler di antara grup hidroksil pada rantai yang berdekatan untuk ukuran granula pati yang besar akan menghasilkan pembengkakan yang lebih besar dibandingkan dengan ukuran granula pati yang kecil (Wattanachant et al., 2002). Ukuran rata-rata granula pati sagu jika dibandingkan jenis pati yang lain tergolong besar, yaitu berkisar antara 72,9-123,4 $\mu \mathrm{m}$ di bawah mikroskop cahaya polarisasi dengan perbesaran $400 \mathrm{X}$ (Gambar 1).

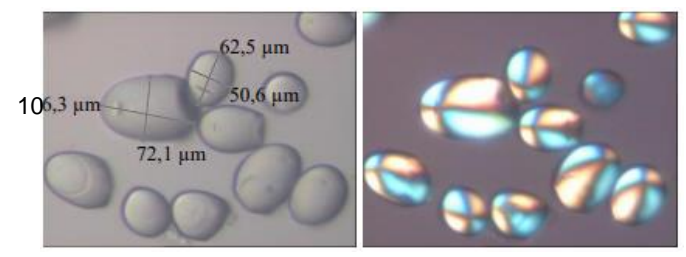

(a)

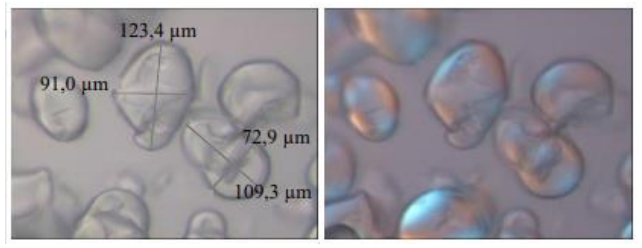

(b)

Gambar 1. Bentuk granula (a) pati sagu alami, (b) pati sitrat

\section{KESIMPULAN}

Proses pembuatan pati sitrat skala laboratorium dan komersial mengalami perbedaan pada sifat fungsional produk yang dihasilkan. Persentase kelarutan, swelling power, dan freeze thaw stability pada pati sitrat skala komersial lebih tinggi dibandingkan skala laboratorium, yaitu sebesar $12.40,4.79$, dan $3.21 \%$. Namun nilai swelling power dan freeze thaw stability tidak berpengaruh signifikan $(\alpha>0.05)$ sedangkan persentase kejernihan pasta $1 \%$ mengalami penurunan sebesar $8.04 \%$. Meskipun memiliki nilai kelarutan dan kejernihan pasta yang berbeda signifikan, pati sitrat skala komersial layak digunakan sebagai bahan dasar pelapis buah terolah minimal.

\section{DAFTAR PUSTAKA}

Badan Ketahanan Pangan, \& Statistik, B. P. (2019). Neraca Bahan Makanan Indonesia 2017-2019.

Badan Pusat Statistika. (2011). Data Statistik Perdagangan Ekspor dan Impor Pati Termodifikasi dan Dekstrin Periode 2008-2010. https://www.bps.go.id

Bello-Perez, E., Agama-Acevedo, P. ., Zamudio-Flores, G., Mendez-Montealvo, S. ., \& Rodriguez-Ambriz. (2010). Effect of low and high acetylation degree in the morphological, physicochemical and structural characteristics of barley starch. Journal Food Science Technology, 43, 1434-1440. https://doi.org/https://doi.org/10.1016/j.lwt.2010.04.00 3

Camirand, W., Pavlath, A., \& Wong, D. (1994). Development of Edible Coatings For Minimally Processed Fruit and Vegetables. Tecnomic. Publ. Co. Inc.

Jading, A., Eduard, T., Paulus, P., \& Sarman, G. (2011). 
Karakteristik fisikokimia pati sagu hasil pengeringan secara fluidisasi menggunakan alat pengering cross flow fluidized bed bertenaga surya dan biomassa. Jurnal Universitas Negeri Papua, 13(3), 155-164. https://doi.org/https://doi.org/10.14710/reaktor.13.3.15 5-164.

Larasati, D. A. (2017). Sifat Fisik Mekanik Coating Film Berbasis Pati Sagu (Metroxylon sp.) Ikat Silang Asam Sitrat. Institut Pertanian Bogor.

Laurila, E., \& Ahvenainen, R. (2002). Minimal processing of fresh fruits and vegetables. In Fruit and Vegetable Processing (2nd ed.). CRC Press. https://doi.org/10.1533/9781855736641.3.288

Lin D, \& Zhao Y. (2007). Innovation in the development and application of edible coating for fresh and minimally processed fruits and vegetables. Comprehensive Reviews in Food Science and Food Safety, 6, 60-75. https://doi.org/https://doi/pdf/10.1111/j.15414337.2007.00018

Perez, L., Acevedo, E., Hernandez, L., \& Lopez, O. (2007). Isolation and partical characterization of banana starch. Journal Agriculture Food Chemical, 48, 845857. https://doi.org/https://doi: 10.1021/jf980828t

Retnaningtyas, D., \& Putri, W. (2014). Karakteristik sifat fisikokimia pati ubi jalar oranye hasil modifikasi perlakuan STPP (Lama Perendaman dan Konsentrasi). Jurnal Pangan Agroindustri, 2(4), 6877.

https://doi.org/https://jpa.ub.ac.id/index.php/jpa/article/ view/79

Saputra, A., Luthfi, E., \& Masruroh, E. (2015). Studi Pembuatan Karakteristik Sifat Mekanik Plastik Biodegradable Berbahan Dasar Ubi Suweg (Amorphophallus campanulatus). Jurnal Keteknikan Pertanian Tropis Dan Biosistem, 3(1), 1-6.

Singh, J. (2004). Effect of accetilation on some properties of corn and potato starches. Starch/Starke, 56, 586601. https://doi.org/https://doi:10.1002/star.200400293

Wattanachant, S., Muhammad, S., Hashim, D., \& Rahman, R. (2002). Characterisation of hydroxypropylated crosslinked sago strach as compared to commercial modified starchs. Journal Science Technology, 24, 439-450.

Winarno, F. (1992). KImia Pangan dan Gizi. Gramedia.

Yuliasih, I., Irawadi, T., Sailah, I., Pranamuda, H., Setyowati, K., \& Sunarti, T. (2008). Pengaruh proses fraksinasi pati sagu terhadap karakteristik fraksi amilosanya. Jurnal Teknologi Industri Pertanian, 17(1), 29-36.

Yuwono, S., S., Febrianto, K., \& Dewi, N., S. (2013). Pembuatan berat tiruan berbasis Modified Cassava Flour (MOCAF): kajian proporsi MOCAF: tepung beras penambahan tepung porang. Jurnal Teknologi Pertanian, 14(3), 175-183. 